\title{
Inhibitors Targeting ABA Biosynthesis and Catabolism Can Be Used to Accurately Discriminate between Haploid and Diploid Maize Kernels during Germination
}

\author{
Jun Soo Kwak ${ }^{1}$, Sung-Il Kim ${ }^{1}$, Jong Tae Song ${ }^{2}$, Si Wan Ryu ${ }^{3}$, Hak Soo Seo ${ }^{1}$ * \\ ${ }^{1}$ Department of Plant Science, Research Institute for Agriculture and Life Sciences, and Plant Genomics and Breeding Institute, \\ Seoul National University, Seoul 08826, Korea \\ ${ }^{2}$ School of Applied Biosciences, Kyungpook National University, Daegu 41566, Korea \\ ${ }^{3}$ Maize Experiment Station, Gangwondo Agricultural Research and Extension Services, Chuncheon 24226, Korea
}

\begin{abstract}
There is a growing preference for using doubled haploids (DHs) in maize breeding programs because they reduce the time required to generate and evaluate new lines to 2 years or less. However, there is an urgent need for efficient techniques that accurately discriminate between haploid and diploid maize kernels. Here, we investigate the effects of several hormones and chemicals on the germination of haploid and diploid maize kernels, including auxin, cytokinin, ethylene, abscisic acid (ABA) biosynthesis inhibitor (fluridone), ABA catabolism inhibitor (diniconazole), methyl jasmonate (MeJA), and NaCl. Ethylene effectively stimulated the germination of both haploid and diploid maize kernels. The ABA biosynthesis inhibitor fluridone, the ABA catabolism inhibitor diniconazole, and MeJA selectively stimulated the germination of haploid maize kernels. By contrast, gibberellin, 1-naphthaleneacetic acid (NAA), kinetin, and $\mathrm{NaCl}$ inhibited the germination of both haploid and diploid maize kernels. These results indicate that the germination of haploid maize kernels is selectively stimulated by fluridone and diniconazole, and suggest that ABA-mediated germination of haploid maize kernels differs from that of diploid maize kernels and other plant seeds.
\end{abstract}

Keywords Haploid, Doubled haploid, Maize, Germination, Fluridone, Diniconazole

\section{INTRODUCTION}

Maize is the first domesticated grain plant and the most widely grown agricultural crop, providing a major resource for food, feed, and biofuels (Godfray et al. 2010). Maize yield can be affected by external and internal factors such as climate conditions, agronomic management, insect and pathogen infection, and fertility efficiency (Lobell et al. 2011; Jin et al. 2012).

Different types of breeding programs have been developed to improve maize growth characteristics and kernel quality. An important aspect of maize breeding programs is the development of homozygous lines. However, conventional breeding is based on recurrent selfing, and it takes approximately six generations to produce homozygous maize lines. Conventional maize breeding programs can be costly because they require substantial time investments (Hallauer et al. 2010). The production of doubled haploid (DH) lines is an important tool in maize breeding because maternal induction of haploids and subsequent doubling and selfing can achieve homozygous lines within two generations (Melchinger et al. 2013). DH lines are produced in maize by in vivo maternal haploid induction (HI) (Prigge et al. 2012), which involves the treatment of desired populations with haploid inducers that generate relatively high frequencies of haploid seeds in the progeny

Received July 27, 2017; Revised August 8, 2017; Accepted August 8, 2017; Published September 1, 2017

*Corresponding author Hak Soo Seo, seohs@snu.ac.kr, Tel: +82-2-880-4548, Fax: +82-2-877-4550 
(Coe 1959; Chaikam 2012; Prigge and Melchinger 2012). The phenomenon of in vivo maternal $\mathrm{HI}$ is unique to maize, although the molecular and biochemical bases have not been clearly identified (Hu et al. 2016). A recent study reported that loss or mutation of a sperm-specific phospholipase triggered $\mathrm{HI}$ in maize (Kelliher et al. 2017; Liu et al. 2017).

The phenotypic expression of $R 1-n j$, termed the Navajo phenotype, is characterized by purple coloration in the aleurone layer on the endosperm crown region and the embryo scutellum (Nanda and Chase 1966; Greenblatt and Bock 1967), which leads to a colored embryo in the hybrid seed versus an uncolored embryo in haploid seed. Although $R 1-n j$ is a good color marker, it has some disadvantages. If the color of the donor seed is dark, it is difficult to accurately perform the visual color selection, and anthocyanin expression can be suppressed in some cases (Röber et al. 2005). It is a time-consuming process because kernel selection is performed manually, and visual inspection of kernels results in approximately $15 \%$ error in haploid selection. Recently, several selection methods with greater accuracy have been reported. Haploid maize kernels can be differentiated from hybrid kernels using near-infrared spectroscopy and soft independent modeling of class analogy; both of these methods achieved higher fidelity than visual inspection of embryo color (Jones et al. 2012).

Considering the time-consuming process required for haploid selection, it is important to effectively screen haploid kernels from hybrid kernels. We are working to develop efficient methods for screening of haploid kernels in maize. Here, we discuss physiological traits that specifically influence the germination of haploid maize kernels. Our results show that fluridone and diniconazole selectively stimulate the germination of haploid maize kernels but not diploid kernels, indicating that these agents can be used to accurately select haploid maize kernels.

\section{MATERIALS AND METHODS}

\section{Plant materials and growth conditions}

Maize seeds (Zea mays L., Gangwon) were surface- sterilized with $50 \%(\mathrm{v} / \mathrm{v})$ sodium hypochlorite solution for 15 minutes and rinsed five times with sterilized deionized water, and then surface-sterilized with $70 \%$ (v/v) ethanol for 5 minutes and washed three times with sterilized deionized water. Finally, the seeds were air-dried at an ambient temperature of $25^{\circ} \mathrm{C}$. For germination tests, ten kernels of haploid or diploid maize were planted on agar plates containing Murashige and Skoog (MS) medium, 1\% sucrose, and $0.8 \%$ agar. All plants were germinated and grown in a growth chamber at $22^{\circ} \mathrm{C}$ under a 16 hour light $/ 8$ hour dark cycle.

\section{Maize kemel germination tests}

Each set of haploid or diploid kernels was plated on MS agar medium or on MS agar medium supplemented with each of the following chemicals: $1 \mu \mathrm{M}$ gibberellin $\left(\mathrm{GA}_{3}\right)$, $150 \mu \mathrm{M}$ methyl jasmonate (MeJA), $50 \mu \mathrm{M}$ ethylene, $1 \mathrm{mM}$ kinetin, $0.01 \mu \mathrm{M}$ 1-naphthaleneacetic acid (NAA), $50 \mathrm{mM}$ $\mathrm{NaCl}, 10 \mu \mathrm{M}$ fluridone, and $10 \mu \mathrm{M}$ diniconazole. The plates were incubated at 22 or $4{ }^{\circ} \mathrm{C}$ for up to 7 days, and the number of germinated kernels was counted each day.

\section{RESULTS}

We explored new approaches to select maize haploids at the time of germination. Haploid kernels germinate slightly later than diploid kernels (Fig. 1). In our germination tests on solid MS medium, haploid kernels began germinating at 4 days after imbibition, whereas diploid kernels began germinating at 3 days after imbibition. These results indicate that diploid kernels germinate 1 day earlier than haploid kernels (Fig. 2 and Table 1).

$\mathrm{GA}_{3}$ stimulates seed germination, whereas abscisic acid (ABA) inhibits germination (Gubler et al. 2005; Finkelstein et al. 2008; Graeber et al. 2012; Hoang et al. 2014). First, we tested the effects of $\mathrm{GA}_{3}$, the ABA biosynthesis inhibitor fluridone, and the $\mathrm{ABA}$ catabolism inhibitor diniconazole. $\mathrm{GA}_{3}$ treatment inhibited the germination of both haploid and diploid kernels, rather than stimulating germination as anticipated (Table 2). By contrast, fluridone stimulated the germination of haploid kernels (Table 3), as did diniconazole (Table 4). Neither fluridone nor 


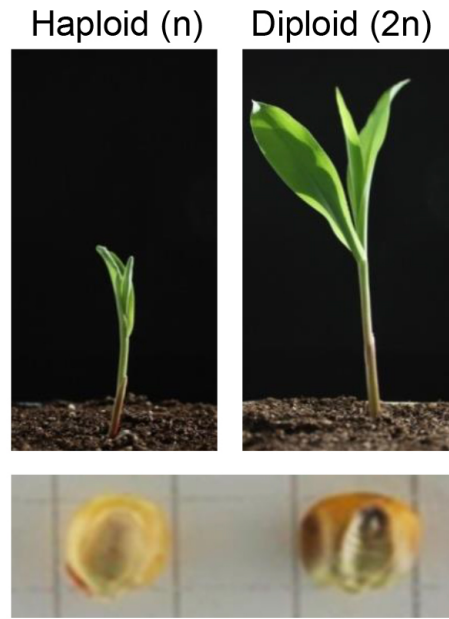

Fig. 1. Phenotypes of haploid and diploid maize kernels and germinated seedlings. Haploid and diploid maize kernels (bottom) were directly sown in soil, germinated, and grown for 7 days (upper). diniconazole affected the germination of diploid kernels (Table 3 and 4), suggesting that both chemicals selectively stimulated the germination of haploid kernels, although the reason remains unknown. The stimulatory effect of diniconazole was greater than that of fluridone. Ethylene also affects seed germination (Beaudoin et al. 2000), and so we examined the effect of ethylene on the germination of haploid and diploid maize kernels. We found that ethylene treatment led to earlier germination for both haploid and diploid kernels, and equally stimulated the germination of both (Table 5).

Auxin and cytokinin regulate plant cell division, growth, and development. Previous studies report that both auxin and cytokinin positively control seed germination (Wang et al. 2011; Liu et al. 2013). Therefore, we tested the effects of auxin and cytokinin. In contrast with earlier reports, our
3
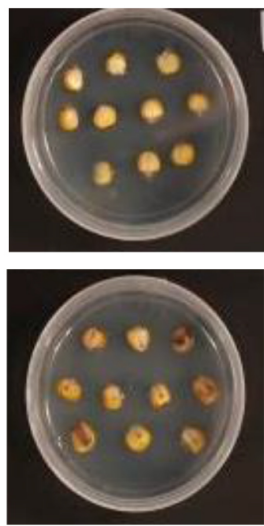

4
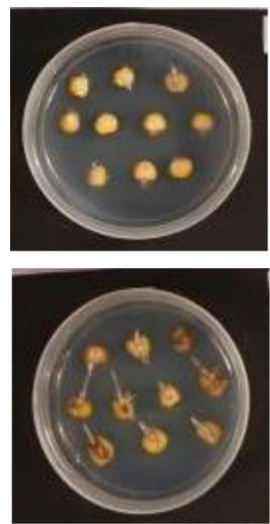

5
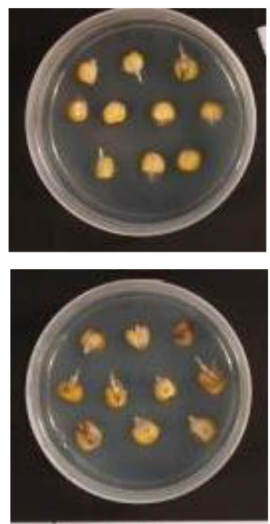

6
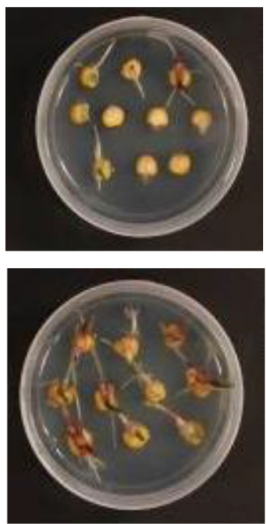

7
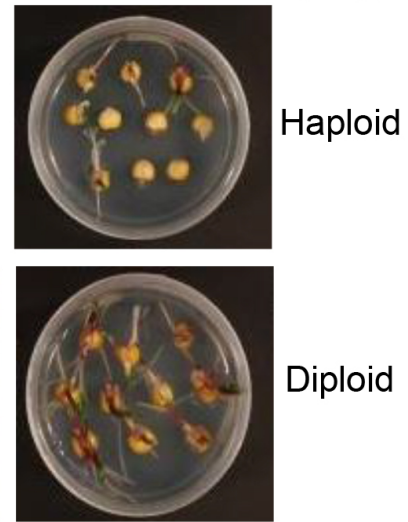

(Day)

Diploid

Fig. 2. Germination of haploid and diploid maize kernels. Haploid and diploid maize kernels were plated on MS agar medium, and germination was recorded by photographing every day for 7 days.

Table 1. Germination rate of haploid and diploid maize kernels on MS medium.

\begin{tabular}{|c|c|c|c|c|c|c|c|c|c|c|c|c|c|c|}
\hline \multirow{2}{*}{$\begin{array}{c}\text { Ten } \\
\text { seeds }\end{array}$} & \multicolumn{7}{|c|}{ Haploid (Day) } & \multicolumn{7}{|c|}{ Diploid (Day) } \\
\hline & 1 & 2 & 3 & 4 & 5 & 6 & 7 & 1 & 2 & 3 & 4 & 5 & 6 & 7 \\
\hline No. 1 & - & - & - & + & + & + & + & - & - & + & + & + & + & + \\
\hline No. 2 & - & - & - & + & + & + & + & - & - & + & + & + & + & + \\
\hline No. 3 & - & - & - & + & + & + & + & - & - & + & + & + & + & + \\
\hline No. 4 & - & - & - & - & + & + & + & - & - & + & + & + & + & + \\
\hline No. 5 & - & - & - & - & - & + & + & - & - & + & + & + & + & + \\
\hline No. 6 & - & - & - & - & - & - & - & - & - & + & + & + & + & + \\
\hline No. 7 & - & - & - & - & - & - & - & - & - & + & + & + & + & + \\
\hline No. 8 & - & - & - & - & - & - & - & - & - & - & + & + & + & + \\
\hline No. 9 & - & - & - & - & - & - & - & - & - & - & - & + & + & + \\
\hline No. 10 & - & - & - & - & - & - & - & - & - & - & - & - & - & - \\
\hline
\end{tabular}


Table 2. Germination rate of haploid and diploid maize kernels on MS medium containing $1 \mu \mathrm{M} \mathrm{GA}_{3}$.

\begin{tabular}{|c|c|c|c|c|c|c|c|c|c|c|c|c|c|c|}
\hline \multirow{2}{*}{$\begin{array}{c}\text { Ten } \\
\text { seeds }\end{array}$} & \multicolumn{7}{|c|}{ Haploid (Day) } & \multicolumn{7}{|c|}{ Diploid (Day) } \\
\hline & 1 & 2 & 3 & 4 & 5 & 6 & 7 & 1 & 2 & 3 & 4 & 5 & 6 & 7 \\
\hline No. 1 & - & - & - & + & + & + & + & - & - & - & + & + & + & + \\
\hline No. 2 & 一 & - & - & - & + & + & + & - & - & - & + & + & + & + \\
\hline No. 3 & - & - & - & - & + & + & + & - & - & - & + & + & + & + \\
\hline No. 4 & 一 & - & - & - & - & - & - & - & - & 一 & + & + & + & + \\
\hline No. 5 & - & - & - & - & - & - & - & - & - & 一 & + & + & + & + \\
\hline No. 6 & - & - & - & - & - & - & - & - & - & - & + & + & + & + \\
\hline No. 7 & - & - & - & - & - & - & - & - & - & 一 & - & + & + & + \\
\hline No. 8 & - & - & - & - & - & - & - & - & - & - & + & + & + & + \\
\hline No. 9 & - & - & - & - & - & - & - & - & - & - & - & - & + & + \\
\hline No. 10 & - & - & - & - & - & - & - & - & - & - & - & - & - & - \\
\hline
\end{tabular}

Table 3. Germination rate of haploid and diploid maize kernels on MS medium containing $10 \mu \mathrm{M}$ fluridone.

\begin{tabular}{|c|c|c|c|c|c|c|c|c|c|c|c|c|}
\hline \multirow{2}{*}{$\begin{array}{c}\text { Ten } \\
\text { seeds }\end{array}$} & \multicolumn{6}{|c|}{ Haploid (Day) } & \multicolumn{6}{|c|}{ Diploid (Day) } \\
\hline & 1 & 2 & 3 & 4 & 5 & 6 & 1 & 2 & 3 & 4 & 5 & 6 \\
\hline No. 1 & - & - & - & - & - & + & - & - & + & + & + & + \\
\hline No. 2 & - & - & - & - & - & - & - & - & + & + & + & + \\
\hline No. 3 & - & - & - & - & - & - & - & - & - & - & + & + \\
\hline No. 4 & - & - & - & - & - & - & - & - & - & - & + & + \\
\hline No. 5 & - & - & - & - & - & - & - & - & - & - & + & + \\
\hline No. 6 & - & - & - & - & - & - & - & - & - & - & + & + \\
\hline No. 7 & - & - & - & - & - & - & - & - & - & - & + & + \\
\hline No. 8 & - & - & - & - & - & - & - & - & - & - & + & + \\
\hline No. 9 & - & - & - & - & - & - & - & - & - & - & - & - \\
\hline No. 10 & - & - & - & - & - & - & - & - & - & - & - & - \\
\hline
\end{tabular}

Table 4. Germination rate of haploid and diploid maize kernels on MS medium containing $10 \mu \mathrm{M}$ diniconazole.

\begin{tabular}{|c|c|c|c|c|c|c|c|c|c|c|c|c|}
\hline \multirow{2}{*}{$\begin{array}{c}\text { Ten } \\
\text { seeds }\end{array}$} & \multicolumn{6}{|c|}{ Haploid (Day) } & \multicolumn{6}{|c|}{ Diploid (Day) } \\
\hline & 1 & 2 & 3 & 4 & 5 & 6 & 1 & 2 & 3 & 4 & 5 & 6 \\
\hline No. 1 & - & - & - & + & + & + & - & - & + & + & + & + \\
\hline No. 2 & - & - & - & + & + & + & - & - & + & + & + & + \\
\hline No. 3 & - & - & - & 一 & - & + & - & - & - & + & + & + \\
\hline No. 4 & - & - & - & - & - & + & - & - & - & + & + & + \\
\hline No. 5 & - & - & - & - & - & - & - & - & - & - & - & - \\
\hline No. 6 & - & - & - & - & - & - & - & - & - & - & - & - \\
\hline No. 7 & - & - & - & - & - & - & - & - & - & - & - & - \\
\hline No. 8 & - & - & - & - & - & - & - & - & - & - & - & - \\
\hline No. 9 & - & - & - & - & - & - & - & - & - & - & - & - \\
\hline No. 10 & 一 & 一 & 一 & 一 & - & 一 & 一 & 一 & - & - & - & - \\
\hline
\end{tabular}

results showed that the germination of haploid and diploid maize kernels was significantly inhibited by NAA or kinetin treatment (Table 6 and 7).

MeJA is a volatile organic compound that is involved in many plant developmental pathways, including seed germination, fruit ripening, senescence, and plant defense (Cheong and Choi 2003). Next, we tested the effect of MeJA on the germination of haploid and diploid maize 
Table 5. Germination rate of haploid and diploid maize kernels on MS medium containing $50 \mu \mathrm{M}$ ethylene.

\begin{tabular}{|c|c|c|c|c|c|c|c|c|c|c|c|c|}
\hline \multirow{2}{*}{$\begin{array}{c}\text { Ten } \\
\text { seeds }\end{array}$} & \multicolumn{6}{|c|}{ "Haploid (Day) } & \multicolumn{6}{|c|}{ Diploid (Day) } \\
\hline & 1 & 2 & 3 & 4 & 5 & 6 & 1 & 2 & 3 & 4 & 5 & 6 \\
\hline No. 1 & - & + & + & + & + & + & - & - & + & + & + & + \\
\hline No. 2 & - & - & + & + & + & + & - & - & + & + & + & + \\
\hline No. 3 & - & - & + & + & + & + & - & - & + & + & + & + \\
\hline No. 4 & - & - & + & + & + & + & - & - & + & + & + & + \\
\hline No. 5 & - & - & - & + & + & + & - & - & + & + & + & + \\
\hline No. 6 & - & - & - & + & + & + & - & - & + & + & + & + \\
\hline No. 7 & - & - & - & + & + & + & - & - & - & + & + & + \\
\hline No. 8 & - & - & - & - & - & - & - & - & - & + & + & + \\
\hline No. 9 & - & - & - & - & - & - & - & - & - & - & + & + \\
\hline No. 10 & - & - & - & - & - & - & - & - & - & - & - & + \\
\hline
\end{tabular}

Table 6. Germination rate of haploid and diploid maize kernels on MS medium containing $0.01 \mu \mathrm{M}$ NAA.

\begin{tabular}{|c|c|c|c|c|c|c|c|c|c|c|c|c|}
\hline \multirow{2}{*}{$\begin{array}{c}\text { Ten } \\
\text { seeds }\end{array}$} & \multicolumn{6}{|c|}{ Haploid (Day) } & \multicolumn{6}{|c|}{ Diploid (Day) } \\
\hline & 1 & 2 & 3 & 4 & 5 & 6 & 1 & 2 & 3 & 4 & 5 & 6 \\
\hline No. 1 & - & + & + & + & + & + & - & + & + & + & + & + \\
\hline No. 2 & - & - & + & + & + & + & - & + & + & + & + & + \\
\hline No. 3 & - & - & + & + & + & + & - & + & + & + & + & + \\
\hline No. 4 & - & - & + & + & + & + & - & + & + & + & + & + \\
\hline No. 5 & - & - & + & + & + & + & - & - & + & + & + & + \\
\hline No. 6 & - & - & + & + & + & + & - & - & + & + & + & + \\
\hline No. 7 & - & - & - & + & + & + & - & - & + & + & + & + \\
\hline No. 8 & - & - & - & + & + & + & - & - & + & + & + & + \\
\hline No. 9 & - & - & - & + & + & + & - & - & + & + & + & + \\
\hline No. 10 & - & - & - & + & + & + & - & - & + & + & + & + \\
\hline
\end{tabular}

Table 7. Germination rate of haploid and diploid maize kernels on MS medium containing 1 mM kinetin.

\begin{tabular}{|c|c|c|c|c|c|c|c|c|c|c|c|c|}
\hline \multirow{2}{*}{$\begin{array}{c}\text { Ten } \\
\text { seeds }\end{array}$} & \multicolumn{6}{|c|}{ Haploid (Day) } & \multicolumn{6}{|c|}{ Diploid (Day) } \\
\hline & 1 & 2 & 3 & 4 & 5 & 6 & 1 & 2 & 3 & 4 & 5 & 6 \\
\hline No. 1 & - & - & + & + & + & + & - & - & + & + & + & + \\
\hline No. 2 & - & - & + & + & + & + & - & - & + & + & + & + \\
\hline No. 3 & - & - & + & + & + & + & - & - & + & + & + & + \\
\hline No. 4 & - & - & + & + & + & + & - & - & + & + & + & + \\
\hline No. 5 & - & - & - & + & + & + & - & - & + & + & + & + \\
\hline No. 6 & - & - & - & + & + & + & - & - & + & + & + & + \\
\hline No. 7 & - & - & - & + & + & + & - & - & + & + & + & + \\
\hline No. 8 & - & - & - & - & + & + & - & - & - & + & + & + \\
\hline No. 9 & - & - & - & - & + & + & - & - & - & - & + & + \\
\hline No. 10 & - & - & - & - & + & + & - & - & - & - & - & + \\
\hline
\end{tabular}

kernels. We found that haploid kernel germination was slightly induced by MeJA, whereas it had no effect on diploid kernel germination (Table 8).

In general, the germination of most plant seeds is inhibited under saline conditions (Ibrahim 2016), and a wide range of $\mathrm{NaCl}$ concentrations inhibit seed germination (Saleki et al. 1993). Therefore, we tested the effects of low $\mathrm{NaCl}$ concentrations on the germination of haploid 
Table 8. Germination rate of haploid and diploid maize kernels on MS medium containing $150 \mu \mathrm{M}$ MeJA.

\begin{tabular}{|c|c|c|c|c|c|c|c|c|c|c|c|c|}
\hline \multirow{2}{*}{$\begin{array}{c}\text { Ten } \\
\text { seeds }\end{array}$} & \multicolumn{6}{|c|}{ Haploid (Day) } & \multicolumn{6}{|c|}{ Diploid (Day) } \\
\hline & 1 & 2 & 3 & 4 & 5 & 6 & 1 & 2 & 3 & 4 & 5 & 6 \\
\hline No. 1 & - & - & + & + & + & + & - & - & + & + & + & + \\
\hline No. 2 & - & - & + & + & + & + & - & - & + & + & + & + \\
\hline No. 3 & - & - & + & + & + & + & - & - & + & + & + & + \\
\hline No. 4 & - & - & + & + & + & + & - & - & + & + & + & + \\
\hline No. 5 & - & - & + & + & + & + & - & - & + & + & + & + \\
\hline No. 6 & - & - & + & + & + & + & 一 & - & + & + & + & + \\
\hline No. 7 & - & - & + & + & + & + & - & - & + & + & + & + \\
\hline No. 8 & - & - & + & + & + & + & - & - & - & + & + & + \\
\hline No. 9 & - & - & - & + & + & + & 一 & - & - & + & + & + \\
\hline No. 10 & - & 一 & - & + & + & + & 一 & - & - & + & + & + \\
\hline
\end{tabular}

Table 9. Germination rate of haploid and diploid maize kernels on MS medium containing $50 \mathrm{mM} \mathrm{NaCl}$.

\begin{tabular}{|c|c|c|c|c|c|c|c|c|c|c|c|c|}
\hline \multirow{2}{*}{$\begin{array}{c}\text { Ten } \\
\text { seeds }\end{array}$} & \multicolumn{6}{|c|}{ Haploid (Day) } & \multicolumn{6}{|c|}{ Diploid (Day) } \\
\hline & 1 & 2 & 3 & 4 & 5 & 6 & 1 & 2 & 3 & 4 & 5 & 6 \\
\hline No. 1 & - & - & - & + & + & + & - & - & - & + & + & + \\
\hline No. 2 & - & - & - & - & - & - & - & - & - & - & - & - \\
\hline No. 3 & - & - & - & - & - & - & - & - & 一 & - & - & 一 \\
\hline No. 4 & - & - & - & - & - & - & - & - & - & - & - & - \\
\hline No. 5 & - & - & - & - & - & - & - & - & - & - & - & 一 \\
\hline No. 6 & - & - & - & - & - & - & - & - & - & - & - & - \\
\hline No. 7 & - & - & - & - & - & - & - & - & - & - & - & - \\
\hline No. 8 & - & - & - & - & - & - & - & - & 一 & - & - & - \\
\hline No. 9 & - & - & - & - & - & - & - & - & - & - & - & - \\
\hline No. 10 & - & - & - & - & - & - & - & - & - & - & - & - \\
\hline
\end{tabular}

and diploid maize kernels. The results showed that $50 \mathrm{mM}$ $\mathrm{NaCl}$ significantly inhibited the germination of both haploid and diploid maize kernels (Table 9).

\section{DISCUSSION}

GA and ABA are the primary hormones that antagonistically regulate seed dormancy and germination (Gubler et al. 2005; Finkelstein et al. 2008; Graeber et al. 2012; Hoang et al. 2014). The endogenous ABA level in seed is downregulated before the onset of germination, whereas the endogenous GA content is upregulated in response to imbibition and stratification. Fluridone is an inhibitor of carotenoid biosynthesis, and inhibits ABA biosynthesis. The germination of fluridone-treated Lolium rigidum seeds was stimulated, suggesting that fluridone acts as a germination stimulant (Goggin and Powles 2014). Our data showed that fluridone treatment only stimulated the germination of haploid maize kernels (Table 3). Diniconazole is a potent competitive inhibitor of ABA 8'-hydroxylase and effectively inhibits ABA catabolism (Kitahata et al. 2005). Diniconazole-mediated inhibition of ABA catabolism arrested seed germination in rice (Zhu et al. 2009). Diniconazole treatment also potentiated the glucose-induced delay in rice (Zhu et al. 2009) and Arabidopsis (Zhu et al. 2011) seed germination. Diniconazole treatment led to rupture of the testa (seed coat) (Carrillo-Barral et al. 2014). All of these results strongly indicate that diniconazole inhibits seed germination. By contrast, our data showed that diniconazole had a positive effect on the germination of haploid kernels (Table 4). Conversely, neither fluridone nor diniconazole affected the germination of diploid maize seeds (Table 3 and 4). Our 
results are not in agreement with previously reported data, suggesting that $\mathrm{ABA}$ synthesis, $\mathrm{ABA}$ catabolism, or ABA-mediated germination of maize kernels may differ from that of other plant seeds.

Ethylene and ABA antagonistically affect seed germination in Arabidopsis (Beaudoin et al. 2000; Ghassemian et al. 2000; Linkies et al. 2009; Arc et al. 2013). For example, the germination of ethylene-insensitive mutants is hypersensitive to ABA (Beaudoin et al. 2000; Ghassemian et al. 2000). Previous studies suggested that $\mathrm{ABA}$ inhibited root growth through the ethylene signaling pathway, but ethylene production (Beaudoin et al. 2000; Ghassemian et al. 2000), suggesting that ethylene was negatively regulated by ABA. Our results showed that ethylene stimulated the germination of both haploid and diploid maize kernels (Table 5).

Auxin is a phytohormone that induces seed dormancy, and maintains seed dormancy through AUXIN RESPONSE FACTOR 10/16-mediated expression of ABA-insensitive 3, a key regulator in the ABA-mediated seed dormancy pathway (Liu et al. 2013). Auxin also acts as a positive regulator of gemma dormancy in liverwort (Eklund et al. 2015). Overexpression of isopentyl transferase led to elevated cytokinin levels in Arabidopsis, which downregulated $\mathrm{ABA}$ signaling and mitigated $\mathrm{ABA}$-mediated suppression of seed germination. ABA attenuates cytokinin biosynthesis by limiting the expression of isopentyl transferase genes, thereby attenuating cytokinin action (Wang et al. 2011). Our results showed that auxin and cytokinin inhibited the germination of both haploid and diploid maize kernels (Table 6 and 7), suggesting that auxin- and cytokinin-mediated germination pathways of maize kernels may differ from those of other plant seeds.

Jasmonate is involved in seed germination as a plant growth regulator. In some cases, jasmonate inhibited the germination of non-dormant seeds and stimulated the germination of dormant seeds. For example, jasmonate stimulates the germination of dormant apple embryo, but inhibited the germination of sunflower, wheat, and oat seeds (Nojavan-Asghari and Ishizawa 1998). MeJA also can stimulate germination of wheat by reducing dormancy (Jacobsen et al. 2013). The effect of MeJA stimulated the germination of haploid maize kernels, but did not affect the germination of diploid maize kernels (Table 8), suggesting that the jasmonate-responsive pathway is activated in haploid maize kernels but not in diploid maize kernels.

In conclusion, we found that the ABA synthesis and catabolism inhibitors fluridone and diniconazole, respectively, stimulated the germination of haploid maize kernels but not diploid maize kernels. These results suggest that ABA signaling differs between haploid and diploid kernels during germination. The phytohormone growth stimulators GA, auxin, and cytokinin inhibited the germination of both haploid and diploid maize kernels. Future studies using different hormone concentrations and germination conditions will provide clues as to why the effects of these hormones on the germination of maize kernels differ from those on other plant seeds. We identified differences in ABA-mediated germination between haploid and diploid kernels, which can be used to distinguish haploid maize kernels from diploid maize kernels during germination or soon thereafter.

\section{ACKNOWLEDGEMENTS}

This work was supported by a grant from the NextGeneration BioGreen 21 Program (Plant Molecular Breeding Center, grant no. PJ01176902), Rural Development Administration, Republic of Korea.

\section{REFERENCES}

Arc E, Sechet J, Corbineau F, Rajjou L, Marion-Poll A. 2013. ABA crosstalk with ethylene and nitric oxide in seed dormancy and germination. Front. Plant Sci. 4: 63.

Beaudoin N, Serizet C, Gosti F, Giraudat J. 2000. Interactions between abscisic acid and ethylene signaling cascades. Plant Cell 12: 1103-1115.

Carrillo-Barral N, Matilla AJ, Rodríguez-Gacio Mdel C, Iglesias-Fernández R. 2014. Nitrate affects sensu-stricto germination of after-ripened Sisymbrium officinale seeds by modifying expression of SoNCED5, SoCYP707A2 and SoGA3ox2 genes. Plant Sci. 217-218: 99-108.

Chaikam V. 2012. In vivo maternal haploid induction in maize, p. 14-19. In: B. Prasanna, V. Chaikam, G. Mahuku 
(eds). Doubled haploid technology in maize breeding: theory and practice. CIMMYT, Mexico, DF.

Cheong JJ, Choi YD. 2003. Methyl jasmonate as a vital substance in plants. Trends Genet. 9: 409-413.

Coe EH. 1959. A line of maize with high haploid frequency. Am. Nat. 93: 381-382.

Eklund DM, Ishizaki K, Flores-Sandoval E, Kikuchi S, Takebayashi Y, Tsukamoto S, et al. 2015. Auxin produced by the indole-3-pyruvic acid pathway regulates development and gemmae dormancy in the liverwort Marchantia polymorpha. Plant Cell 27: 1650-1669.

Finkelstein R, Reeves W, Ariizumi T, Steber C. 2008. Molecular aspects of seed dormancy. Annu Rev Plant Biol 59: 387-415.

Ghassemian M, Nambara E, Cutler S, Kawaide H, Kamiya Y, McCourt P. 2000. Regulation of abscisic acid signaling by the ethylene response pathway in Arabidopsis. Plant Cell 12: 1117-1126.

Godfray HCJ, Beddington JR, Crute IR, Haddad L, Lawrence D, Muir JF, et al. 2010. Food security: the challenge of feeding 9 billion people. Science 327: 812-818.

Goggin DE, Powles SB. 2014. Fluridone: a combination germination stimulant and herbicide for problem fields? Pest Manag. Sci. 70: 1418-1424.

Graeber K, Nakabayashi K, Miatton E, Leubner-Metzger G, Soppe WJ. 2012. Molecular mechanisms of seed dormancy. Plant Cell Environ. 35: 1769-1786.

Greenblatt IM, Bock M. 1967. A commercially desirable procedure for detection of monoploids in maize. J. Hered. 58: 9-13.

Gubler F, Millar AA, Jacobsen JV. 2005. Dormancy release, ABA and pre-harvest sprouting. Curr. Opin. Plant Biol. 8: 183-187.

Hallauer AR, Carena MJ, Miranda Filho JB. 2010. Quantitative genetics in maize breeding. 3rd ed. Spring, NY.

Hoang HH, Sechet J, Bailly C, Leymarie J, Corbineau F. 2014. Inhibition of germination of dormant barley (Hordeum vulgare L.) grains by blue light as related to oxygen and hormonal regulation. Plant Cell Environ. 37: 1393-1403.

Hu H, Schrag TA, Peis R, Unterseer S, Schipprack W, Chen $\mathrm{S}$, et al. 2016. The genetic basis of haploid induction in maize identified with a novel Genome-Wide Association Method. Genetics 202: 1267-1276.

Ibrahim EA. 2016. Seed priming to alleviate salinity stress in germinating seeds. J Plant Physiol. 192: 38-46.

Jacobsen JV, Barrero JM, Hughes T, Julkowska M, Taylor $\mathrm{JM}, \mathrm{Xu} \mathrm{Q}$, et al. 2013. Roles for blue light, jasmonate and nitric oxide in the regulation of dormancy and germination in wheat grain (Triticum aestivum L.). Plant 238: $121-138$

Jin L, Cui H, Li B, Zhang J, Dong S, Liu P. 2012. Effects of integrated agronomic management practices on yield and nitrogen efficiency of summer maize in North China. Field Crops Res. 134: 30-35.

Jones RW, Reinot T, Frei UK, Tseng Y, Lübberstedt T, McClelland, JF. 2012. Selection of haploid maize kernels from hybrid kernels for plant breeding using near-infrared spectroscopy and SIMCA analysis. Appl. Spectrosc. 66: 447-450.

Kelliher T, Starr D, Richbourg L, Chintamanani S, Delzer B, Nuccio ML, et al. 2017. MATRILINEAL, a sperm-specific phospholipase, triggers maize haploid induction. Nature 542: 105-109.

Kitahata N, Saito S, Miyazawa Y, Umezawa T, Shimada Y, Min YK, et al. 2005. Chemical regulation of abscisic acid catabolism in plants by cytochrome P450 inhibitors. Bioorg. Med. Chem. 13: 4491-4498.

Linkies A, Muller K, Morris K, Turečková V, Wenk M, Cadman CSC, et al. 2009. Ethylene interacts with abscisic acid to regulate endosperm rupture during germination: a comparative approach using Lepidium sativum and Arabidopsis thaliana. Plant Cell 21: 3803-3822.

Liu C, Li X, Meng D, Zhong Y, Chen C, Dong X, et al. 2017. A 4-bp insertion at ZmPLA1 encoding a putative phospholipase A generates haploid induction in maize. Mol. Plant 10: 520-522.

Liu X, Zhang H, Zhao Y, Feng Z, Li Q, Yang HQ, et al. 2013. Auxin controls seed dormancy through stimulation of abscisic acid signaling by inducing ARF-mediated ABI3 activation in Arabidopsis. Proc. Natl. Acad. Sci. USA. 110: 15485-15490.

Lobell DB, Schlenker W, Costa-Roberts J. 2011. Climate trends and global crop production since 1980. Science 333: 616-620.

Melchinger AE, Schipprack W, Würschum T, Chen S, Technow F. 2013. Rapid and accurate identification of in vivo-induced haploid seeds based on oil content in maize. Sci. Rep. 3: 2129.

Nanda, DK, Chase SS. 1966. An embryo marker for detecting 
monoploids of maize (Zea mays L.). Crop Sci. 6: 213-215.

Nojavan-Asghari M, Ishizawa K. 1998. Inhibitory effects of Methyl jasmonate on the germination and ethylene production in cocklebur seeds. J, Plant Growth Regul. 17: 13-18.

Prigge V, Xu X, Li L, Babu R, Chen S, Atlin GN, et al. 2012. New insights into the genetics of in vivo induction of maternal haploids, the backbone of doubled haploid technology in maize. Genetics 190: 781-793.

Prigge V, Melchinger AE. 2012. Production of haploids and doubled haploids in maize, p. 161-172. In: VM LoyolaVargas, N. Ochoa-Alejo (eds). Plant cell culture protocols. Springer, New Jersey.

Röber FK, Gordillo GA, Geiger HH. 2005. In vivo haploid induction in maize-performance of new inducers and significance of doubled haploid lines in hybrid breeding.
Maydica 50: 275-283.

Saleki R, Young PG, Lefebvre DD. 1993. Mutants of Arabidopsis thaliana capable of germination under saline conditions. Plant Physiol. 101: 839-845.

Wang Y, Li L, Ye T, Zhao S, Liu Z, Feng YQ, et al. 2011. Cytokinin antagonizes ABA suppression to seed germination of Arabidopsis by downregulating ABI5 expression. Plant J. 68: 249-261.

Zhu G, Liu Y, Ye N, Liu R, Zhang J. 2011. Involvement of the abscisic acid catabolic gene CYP707A2 in the glucoseinduced delay in seed germination and post-germination growth of Arabidopsis. Physiol. Plant. 143: 375-384.

Zhu G, Ye N, Zhang J. 2009. Glucose-induced delay of seed germination in rice is mediated by the suppression of ABA catabolism rather than an enhancement of ABA biosynthesis. Plant Cell Physiol. 50: 644-651. 